\title{
Effects of Viral Exposure of the Two-Cell Mouse Embryo on Cleavage and Blastocyst Formation In Vitro
}

\author{
ALFRED D. HEGGIE (25) AND LUCILE GADDIS \\ Department of Pediatrics, Case Western Reserve University School of Medicine, and Rainbow Babies and Childrens \\ Hospital, Cleveland, Ohio, USA
}

\begin{abstract}
Summary
The effect of viral exposure of two-cell mouse embryos on their capacity to undergo subsequent cleavage and blastocyst formation in vitro was determined. Exposure to Coxsackie viruses B-4 and B-6, reovirus type 2 , influenza virus type $A$, mouse cytomegalovirus, adenovirus type 5 , and mouse adenovirus resulted in statistically significant inhibition of blastocyst formation. Development in vitro was unaffected by exposure to ECHO virus type 11, attenuated poliomyelitis virus type 2 , parainfluenza virus type 1 , mumps, rubella, and herpes simplex viruses types 1 and 2. Blastocyst formation was also unaffected by exposure of embryos to mouse interferon in a concentration 24 units $/ \mathrm{ml}$ of culture fluid. Coxsackie virus B-4 was recovered from exposed embryos.
\end{abstract}

Speculation

Arrest of cleavage in the preimplantation embryo may be the mechanism by which some maternal viral infections induce reproductive failure. Exposure of embryos to certain viruses, however, fails to interfere with cleavage or blastocyst formation. Further studies are required to determine if these apparently unaffected embryos have sustained occult injury which may result in abnormal development at later stages of gestation.

Investigations of the interactions which occur between viruses and preimplantation mammalian embryos are important because they may contribute to an understanding of the processes by which certain maternal viral infections during early pregnancy induce embryonic death or abnormal development $(5,11)$. The inaccessibility of the preimplantation embryo to direct observation, however, limits studies which can be done in vivo and necessitates the use of in vitro techniques. Although methods for cultivation of preimplantation mammalian embryos in vitro have been available for many years, relatively few studies of the effects of virus exposure on embryos at this early stage of development have been reported. By inoculating cultures of two-cell mouse embryos with the mengo strain of encephalomyocarditis virus, Gwatkin (6-8) first demonstrated that viral exposure may result in arrest of cleavage and degeneration of blastomeres. Exposure of eight-cell mouse embryos to adenovirus type 5 was reported by Chase et al. (4) to arrest cleavage within one cell cycle and Tuffrey et al. (22) noted that when fertilized ova for egg fusion experiments were obtained from mouse colonies where infection with parainfluenza virus type 1 was prevalent, early degeneration of the ova occurred in vitro. In contrast to these reports of injurious effects of viral exposure on fertilized ova and early embryos, Berkovich (2) observed that exposure of fertilized rabbit ova to herpes simplex virus type 1 in vitro had no effect on subsequent cleavage. Similarly, Sawicki et al. (19) and Baranska et al. (1) using SV-40 and Moloney sarcoma viruses, Biczysko et al. (3) using SV-40 and polyoma viruses, and Mohanty and Bachman (16) using minute virus of mice reported that exposure of two-cell mouse embryos to these viruses did not interfere with cleavage and blastocyst formation in vitro. To extend these observations on the interactions between viruses and early embryos, the capacity of two-cell mouse embryos to undergo cleavage and blastocyst formation in vitro after exposure to a spectrum of viruses was determined. Viruses tested included strains from the enterovirus, myxovirus, paramyxovirus, herpesvirus, and adenovirus groups and rubella virus. The effect of exposure of embryos to interferon, a product of viral infection, was also tested.

\section{MATERIALS AND METHODS}

\section{PREPARATION OF VIRUS STOCKS}

Virus stocks were prepared in cell monolayer cultures or in 10day embryonated chick eggs as indicated in Table 1. Uninfected cultures or uninfected eggs served as controls. Cells and fluids were harvested from both infected and control cell cultures and allantoic fluids were collected from infected and control eggs. Cell suspensions were centrifuged at 2000 RPM for $10 \mathrm{~min}$, the supernatant fluids were saved, and the precipitated cells, suspended in a small amount of medium, were disrupted by freezing and thawing 3 times. The suspensions of disrupted cells were centrifuged at $2000 \mathrm{RPM}$ for $10 \mathrm{~min}$, the precipitated buttons of cellular debris were discarded, and the fluids were added to the previously saved supernatant culture fluids, Virus stocks were titered and control fluids were reinoculated into cell cultures to insure that they had not become contaminated by the viruses to be tested. Control fluids, therefore, were identical to virus stocks except that they did not contain virus. In the case of viruses grown in the allantoic sacs of embryonated eggs, allantoic fluids from uninfected eggs served as control fluids.

\section{PREPARATION AND INOCULATION OF EMBRYO CULTURES}

Virgin female CAW:CF\#1 mice, 8-wk-old, were superovulated by injection of two units of pregnant mare serum gonadotropin 48 $\mathrm{hr}$ before mating and two units of human chorionic gonadotropin just before mating with a male of the same strain. Embryos at the two-cell stage of cleavage were harvested $48 \mathrm{hr}$ after mating by flushing the oviducts with Whitten's egg culture medium (23) according to the method described by Rafferty (18). Immediately after being flushed from the oviduct, two-cell embryos were placed in rubber stoppered glass test tubes containing $1.0 \mathrm{ml}$ of Whitten's medium. Each tube culture contained 10-15 embryos and each experiment included three tube cultures. One culture was inoculated with $0.1 \mathrm{ml}$ of a 1:10 dilution of virus stock in Whitten's medium, one culture with $0.1 \mathrm{ml}$ of the same dilution of the control fluid corresponding to the virus preparation, and the third culture served as an uninoculated control. The amount of virus in each inoculum is shown in Table 2. After inoculation, all tube cultures were equilibrated with a mixture of $5 \%$ carbon dioxide, $5 \%$ oxygen, and $90 \%$ nitrogen and were incubated at $37^{\circ}$. Pro- 
Table 1. Preparation of virus stocks

\begin{tabular}{llll}
\hline \multicolumn{1}{c}{ Virus } & \multicolumn{1}{c}{ Strain' } & \multicolumn{1}{c}{ Cell culture or embryonated egg } & \multicolumn{1}{c}{ Indicator of infection } \\
\hline Coxsackie type B-4 & J.V.B. (VR-184) & AGMK & CPE \\
Coxsackie type B-6 & Schmitt (VR-155) & AGMK & CPE \\
ECHO Type 1I & Gregory2 & AGMK & CPE \\
Attenuated polio type 2 & W-2(VR-301) & AGMK & CPE \\
Reovirus type 2 & D-5 Jones (VR-23I) & AGMK & CPE \\
Influenza type A & A/Eng/42/72 & Allantoic sac & Hemagglutination \\
Parainfluenza type 1 & Sendai/52(VR-105) & Allantoic sac & Hemagglutination \\
Mumps & Enders (VR-106) & Allantoic sac & Hemagglutination \\
Rubella & M-33 & AGMK & ECHO virus type 11 interference \\
Herpes simplex type 1 & F(1)(VR-733) & HEp-2 & CPE \\
Herpes simplex type 2 & G(VR-734) & HEp-2 & CPE \\
Mouse cytomegalovirus & Smith MSGV (VR-194) & Primary mouse embryo cells & CPE \\
Adenovirus type 5 & Adenoid 75 (VR-5) & HeLa & CPE \\
Mouse adenovirus & FL (VR-550) & Primary mouse embryo cells & CPE \\
\hline
\end{tabular}

' VR numbers are the catalog numbers of virus strains that were obtained from the American Type Culture Collection, Rockville, MD.

${ }^{2}$ Obtained from Dept. of Virus Diseases, Walter Reed Army Institute for Research, Washington, D.C. Originally received from Dr. A. B. Sabin.

"Obtained from Dr. G. A. Nankervis, Dept. of Pediatrics, Metropolitan General Hospital and Case Western Reserve University, Cleveland, OH.

${ }^{4}$ Allantoic sac of 10 day embryonated chick eggs.

"Obtained from Dr. P. D. Parkman, Bureau of Biologics, Food and Drug Administration, Rockville, MD.

Table 2. Effect of viral exposure of mouse embryos at the two-cell stage on subsequent blastocyst formation in vitro

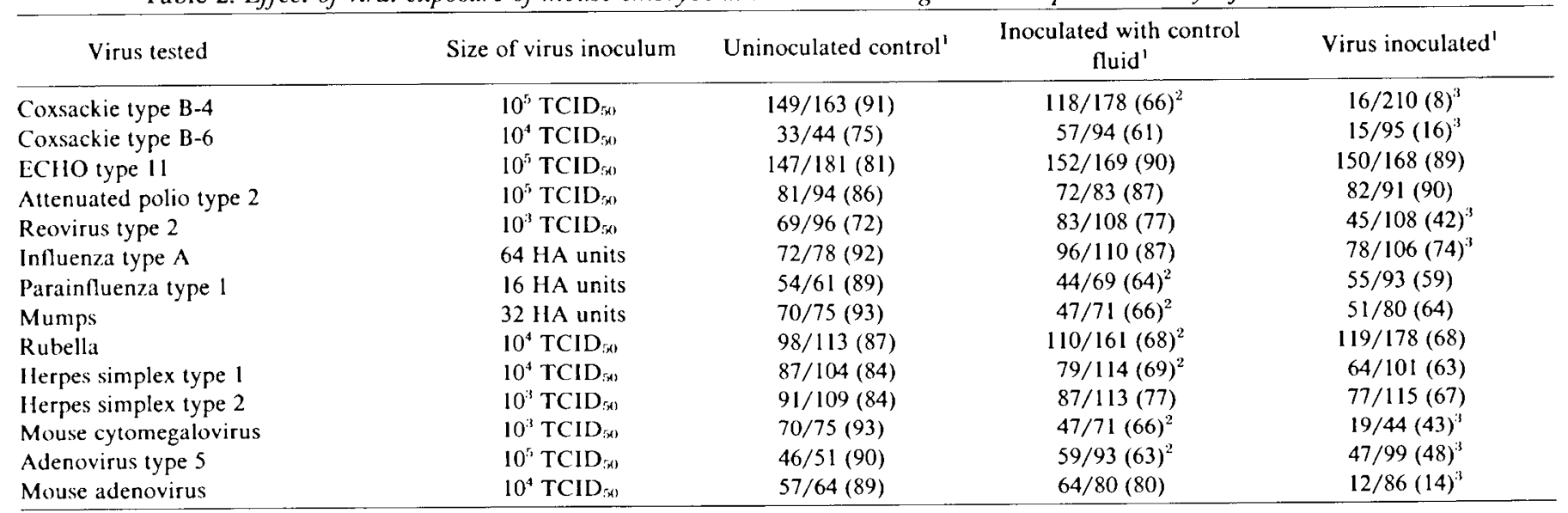

' No. of embryos forming blastocysts/total no. of embryos in culture (\%).

"Statistically significant difference in blastocyst yield between uninoculated control cultures and cultures inoculated with control fluid $(P<0.05$ by the $\chi^{2}$ test).

${ }^{3}$ Statistically significant difference in blastocyst yield between cultures inoculated with control fluid and cultures inoculated with virus $(P<0.05$ by the $\chi^{2}$ (est).

gression of cleavage was observed daily with an inverted microscope and after $72 \mathrm{hr}$ in culture ( 5 days after mating), the proportion of embryos which had developed to the blastocyst stage was determined for each culture. Because blastocyst formation in vitro can be inhibited by a variety of unfavorable environmental conditons, an experiment was considered to be valid only if blastocyst formation occurred in at least $60 \%$ of the embryos both in the uninoculated culture and in the culture inoculated with control fluid. Approximately $25 \%$ of the experiments performed were discarded because of failure to meet this criterion.

\section{TECHNIQUE FOR RECOVERY OF VIRUSES FROM EXPOSED EMBRYOS}

At the conclusion of each experiment, embryos from virus inoculated cultures were collected, washed three times in $1.0 \mathrm{ml}$ of Hank's balanced salt solution (10), and frozen and thawed three times in $1.0 \mathrm{ml}$ of Whitten's medium to disrupt the blastomeres and release any intracellular virus present. Aliquots of this suspension of cell contents and debris, $0.1 \mathrm{ml}$, were then inoculated into appropriate cell cultures growing in the wells of plastic flat bottomed microtiter plates to detect viral infection in exposed embryos. Indicators used to detect infection are listed in Table 1.

\section{ULTRAVIOLET INACTIVATION OF COXSACKIE VIRUS TYPE B-4}

Aliquots of the stock preparation $(2 \mathrm{ml})$ of Coxsackie virus type B- 4 or control fluids were placed in $35 \times 10 \mathrm{~mm}$ plastic petri dishes and irradiated with ultraviolet light $\left(4800 \mu \mathrm{W} / \mathrm{em}^{2}\right)$ for 20 min. Irradiated virus was shown to be inactivated by its failure to produce cytopathic effects (CPE) after inoculation into primary African green monkey kidney (AGMK) monolayer cultures.

\section{INTERFERON}

Mouse interferon with a potency of 12,000 units/ $\mathrm{ml}$ by vesicular stomatitis virus plaque reduction assay was obtained from the Research Resources Branch of the National Institute for Allergy and Infectious Diseases. Inactivated interferon was prepared by autoclaving this material at a pressure of $10 \mathrm{lb} / \mathrm{sq}$ in for $10 \mathrm{~min}$. Embryo cultures were inoculated with 24 units of interferon contained in $0.1 \mathrm{ml}$ aliquots in the same manner as described for 
viruses. Control cultures were inoculated with an equivalent amount of inactivated interferon.

\section{RESULTS}

The proportions of two-cell embryos which developed to the blastocyst stage in uninoculated cultures and in cultures inoculated with control fluids or viruses are shown in Table 2. Inoculation of embryo cultures with control fluids frequently resulted in statistically significant reductions in blastocyst yields when compared with uninoculated cultures. Assessment of the effect of virus exposure, therefore, was always made by comparison of blastocyst yields in virus inoculated cultures with yields in cultures inoculated with control fluids. Exposure of embryos to Coxsackie viruses types B-4 and B-6 (Cox B-4 and Cox B-6), reovirus type 2, influenza virus type $A$, mouse cytomegalovirus (MCMV), adenovirus type 5, and mouse adenovirus resulted in inhibition of blastocyst formation. In embryos exposed to these viruses, cleavage proceeded normally to the 8-16 cell stage, but was arrested at that point in development in a statistically significant proportion of embryos (Table 2). No degeneration of blastomeres occurred in these embryos during the period of observation except in embryos exposed to Cox B-4. These embryos degenerated rapidly after reaching the eight-cell stage. Figure $1 \mathrm{~A}-\mathrm{F}$ compares the development of blastocysts in a culture inoculated with control fluid with the arrest of cleavage and degeneration of blastomeres which occurred consistently in cultures inoculated with Cox B-4. To determine that these effects were related to exposure to live virus and not to some toxic product of viral replication contained in the inoculum, the effects of exposure to live and ultraviolet inactivated Cox B-4 on blastocyst formation were compared. Table 3 demonstrates that blastocyst formation was unaffected by exposure of two-cell embryos to inactivated Cox B-4, whereas, in companion cultures inoculated with live virus, this process was completely inhibited.
Herpes simplex viruses types 1 and 2 (HSV-l and HSV-2) did not interefere with blastocyst formation to a statistically significant degree (Table 2) and no degeneration of blastomeres was observed in embryos exposed to these viruses. As a marker of virulence of the HSV-1 or HSV-2 being used and to ensure that embryos were in constant contact with virus, additional experiments were conducted in which two-cell embryos were cocultivated with primary monolayer cultures of AGMK cells which were then immediately infected with HSV-1 or HSV-2. Cytopathic effects characteristic of HSV-1 or HSV-2 promptly appeared in the cell monolayers, but there was no inhibition of blastocyst formation and no cytopathic changes were observed in the developing embryos (Fig. 2A-D).

Attempts were made to recover Cox B-4, Cox B-6, HSV-1, HSV-2, influenza virus type $A$, and attenuated poliovirus type 2 from exposed embryos after 4 days in culture. Virus was occasionally recovered from embryos exposed to Cox B-4, but attempts to recover the other viruses from exposed embryos were unsuccessful.

In experiments on the effect of exposure to interferon, no statistically significant differences in the proportions of embryos forming blastocysts were demonstrated among cultures inoculated with mouse interferon in a concentration of $24 \mathrm{units} / \mathrm{ml}$ of culture

Table 3. Comparison of effects of exposure of two-cell mouse embryos to live and ultraviolet inactivated Coxsackie virus type B-4 on blastocyst formation in vitro

\begin{tabular}{lc}
\hline \multicolumn{1}{c}{ Inoculum } & Blastocyst formation' \\
\hline Uninoculated & $31 / 39(79)$ \\
Cell culture fluid control & $76 / 112(68)$ \\
Ultraviolet inactivated Coxsackie virus B-4 & $74 / 102(73)$ \\
Live Coxsackie virus B-4 & $0 / 112(0)$ \\
\hline
\end{tabular}

${ }^{1}$ No. of embryos forming blastocysts/no. of embryos in culture (\%).
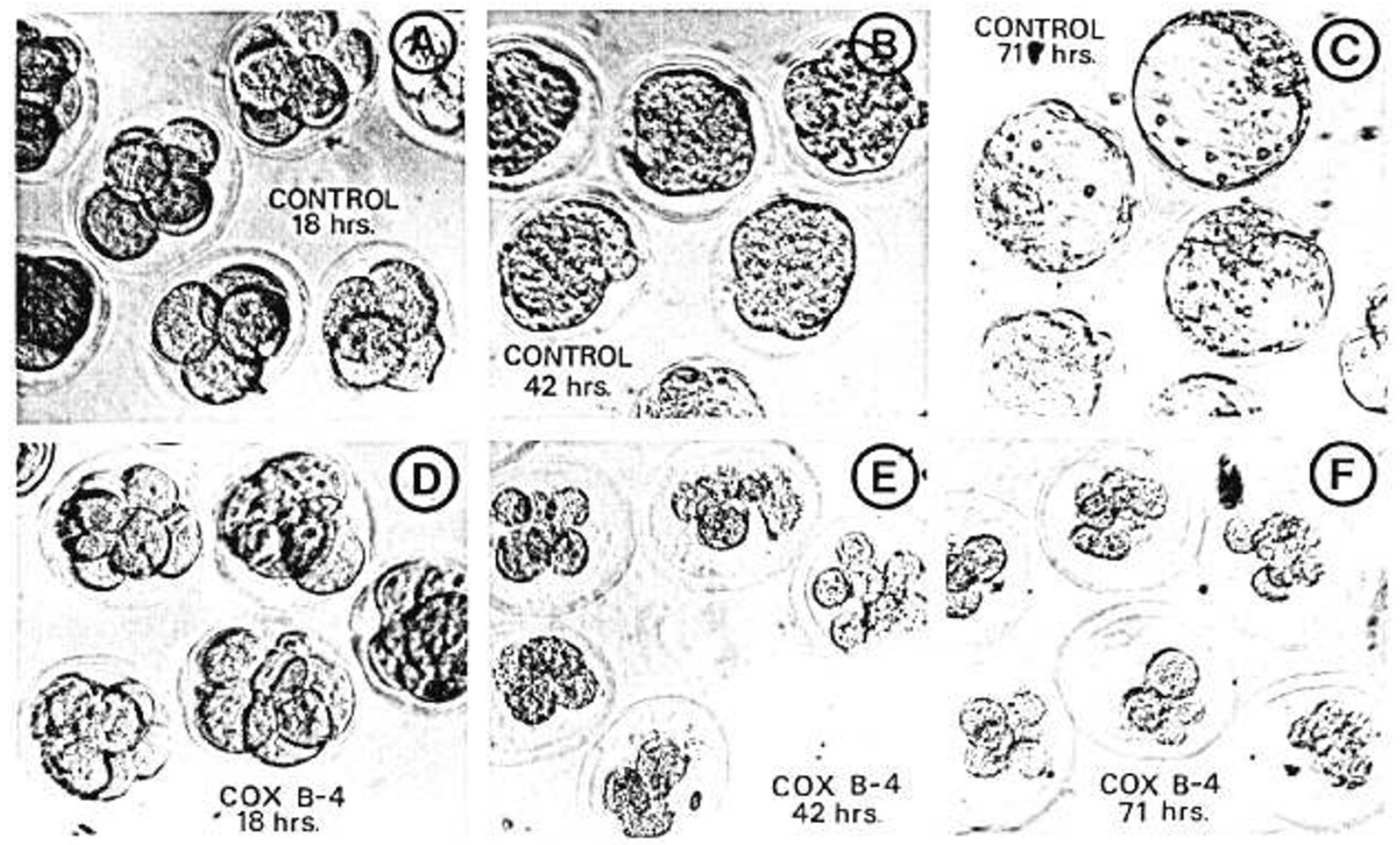

Fig. 1. Cleavage and blastocyst formation in cultures of two-cell mouse embryos after inoculation with Cox B-4 or control fluid. Normal progression through eight-cell, morula, and blastocyst stages at 18,42 , and $71 \mathrm{hr}$ after inoculation with control fluid $(A-C)$. Progression to the eight-cell stage at 18 $\mathrm{hr}$ after inoculation with Cox B-4 $(D)$, but arrest of cleavage and degeneration of blastomeres at $42 \mathrm{and} 71 \mathrm{hr}$ after viral inoculation $(E, F)$. (Magnification X 100). 


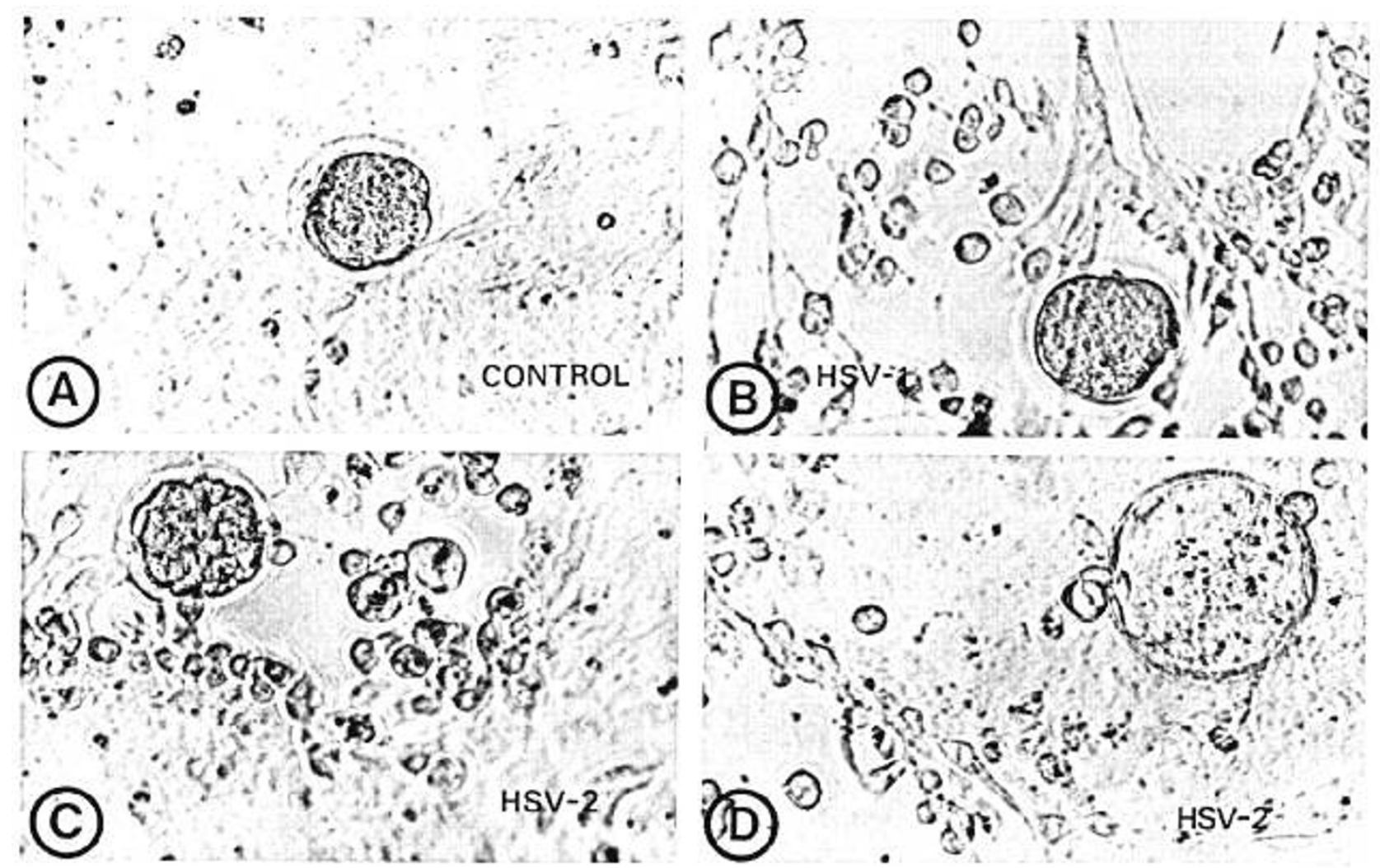

Fig. 2. Representative mouse embryos cocultivated from the two-cell stage in monolayer cultures of AGMK cells inoculated with HSV-I, HSV-2, or control fluid. Normal morula resting on cell monolayer $44 \mathrm{hr}$ after inoculation with control fluids $(A)$. Normal morulae on cell monolayers showing CPE and degeneration $44 \mathrm{hr}$ after inoculation with HSV-1 $(B)$ and HSV-2 $(C)$. Normal blastocyst on cell monolayer showing CPE 72 hr after HSV-2 inoculation $(D)$. (Magnification X 100).

fluid, cultures inoculated with equivalent amounts of heat inactivated interferon, and uninoculated embryo cultures (Table 4).

\section{DISCUSSION}

These investigations demonstrate that development of the preimplantation mouse embryo in vitro is susceptible to arrest by exposure to certain viruses. This arrest is presumed to be the result of viral replication in embryonic cells. Attempts to recover six of the viruses tested from exposed embryos, however, were successful only with Cox B-4 which was detected only in undiluted suspensions of embryonic cells. Failure to detect viruses more readily may be related to the relatively small number of virus-exposed embryonic cells which are available for culture in this experimental system. Other investigators have reported the recovery of SV40 , Moloney sarcoma virus, and minute virus of mice from varying proportions of exposed preimplantation embryos $(1,16,19)$, but quantitation of the amount of virus present was either not attempted or was unsuccessful because virus could be detected only in undiluted suspensions or homogenates of embryonic cells. Any dilution for the purpose of quantitation resulted in negative tests for virus (16). Gwatkin and Auerbach (9) in studies of the replication of encephalomyocarditis virus in fertilized mouse ova concluded that viral replication in early mouse embryos was much less efficient than in primary cultures of mouse fibroblasts. Thus, the amount of virus produced by replication in exposed preimplantation embryos may be small and may require more sensitive methods such as fluorescent or electron microscopy for its detection.

The possibility that arrest of cleavage by some viruses is related to toxicity of viral protein and not to viral infection of embryonic cells must also be considered. In the case of Cox B-4, cleavage arrest was shown to be related to infectivity, because virus that was rendered noninfectious by ultraviolet irradiation did not
Table 4. Effect of exposure of two-cell mouse embryos to interferon on blastocyst formation in vitro

\begin{tabular}{lc}
\hline \multicolumn{1}{c}{ Inoculum } & Blastocyst formation' \\
\hline Uninoculated & $58 / 63(92)$ \\
Inactivated interferon & $48 / 60(80)$ \\
Interferon & $49 / 59(83)$ \\
\hline
\end{tabular}

' No. of embryos forming blastocysts/no. of embryos in culture (\%).

inhibit blastocyst formation. The lack of significant toxicity can also be assumed for those viruses that had no effect on cleavage. The possible role of toxicity in the inhibitory effects on cleavage demonstrated for the other viruses in this study will require additional investigation.

An important aspect in which this study differs from others on the effects of viral exposure on embryonic development in vitro is the inclusion not only of uninoculated control cultures of embryos, but also of control cultures inoculated with fluids from the same batch of cell cultures or embryonated eggs used to prepare the virus stocks. Inoculation of embryo cultures with control fluids for 7 of the 14 viruses tested resulted in statistically significant reductions in blastocyst yields when compared with uninoculated cultures. These reductions were probably related to the presence of inhibitory products of cell metabolism in the control fluids and presumably, therefore, in the virus stocks. The possibility, however, that these reductions resulted from the effects of undetected adventitious agents in the control fluids must also be considered. Although control fluids were reinoculated into the cell lines in which they were prepared to insure that they had not become contaminated by the viruses being tested, adventitious agents may have escaped detection by this procedure. Whatever the nature of this inhibition of blastocyst formation by some control fluids, the inclusion of this type of control is essential to distinguish reduc- 
tions in blastocyst yields caused by extraneous factors from reductions caused by interactions between embryos and the viruses being investigated.

The demonstration by the present study that viral exposure of the early embryo in vitro inhibits cleavage and blastocyst formation suggests a mechanism to explain the reproductive failure associated with some maternal viral infections in early pregnancy. Among the factors determining whether this virus effect occurs in vivo, however, is the ability of a virus to reach the embryo at this stage of development. Because contact between virus and embryo during the preimplantation stage of gestation cannot take place by the transplacental route, access to the embryo at this stage probably requires viral invasion of the tissues of the maternal reproductive tract. Whether exposure of early embryos by this route occurs in vivo can be surmised for several of the viruses tested in this study by comparing the responses of mouse embryos observed after exposure in vitro with reports on the effects of viral inoculation of the female mouse in early gestation on the outcome of pregnancy in vivo. The finding of Hassan and Cochran (12), for example, that pregnancy failed to occur in otherwise healthy female mice that were inoculated with reovirus type 1 within 3 days after mating suggests that reoviruses reach the preimplantation embryo and produce reproductive failure by arrest of cleavage. In contrast to these findings with reovirus, inoculation of female mice with coxsackievirus B-3 just before mating was reported by Soike (21) to have no effect on the outcome of pregnancy, although inoculation later in pregnancy produced transplacental infection and fetal wastage. The discrepancy between this observation in vivo and the finding in the present study that exposure of preimplantation embryos to Cox B-4 and Cox B-6 in vitro results in arrest of cleavage suggests that contact between group B Coxsackie viruses and embryos does not occur during early development in the mouse.

In studies of MCMV infection during pregnancy Medearis (15) and Johnson (13) found that despite extensive fetal wastage, intrauterine infection did not occur. Johnson demonstrated by direct inoculation of mouse embryos, however, that they were susceptible to infection. Neighbour (17) found that MCMV infection caused uterine inflammation and failure of implantation, but that preimplantation embryos harvested from infected mice developed into normal blastocysts in vitro. Thus, although the mouse embryo is susceptible to infection and, as shown in the present study, to developmental interference by MCMV, viral exposure of the embryo does not occur in vivo and reproductive failure is apparently the result of viral effects on maternal tissues. In human cytomegalovirus disease, however, fetal infection is frequent $(5$, 11) and viral interference with blastocyst formation is a possible cause of abnormal development.

Type A influenza virus is another example of a potentially embryopathic virus which apparently does not reach the mouse embryo. In a study in vivo, it was found by Siem et al. (20) that although the pregnancy rate was reduced in female mice inoculated within 7 days after mating, influenza virus could not be detected in the uterine horns. Again, despite its embryopathic potential, the effects of this virus on early development in the mouse appear to be indirect and mediated through effects on the mother.

The failure of HSV-1 and HSV-2 to interfere with cleavage or blastocyst formation in vitro despite their known virulence for suckling and adults mice in vivo, shows that the response of the suckling or adult host to infection is not reliably predictive of the effect of viral exposure on the early embryo. In this study, however, embryonic development was observed only through blastocyst formation. Additional investigations involving transfer of virus exposed embryos to uteri of pseudopregnant recipients to permit continuation of development in vivo might result in detection of virus induced defects which may be present, but inapparent at the blastocyst stage. This technique could also be applied to studies of other viruses which show no effect on embryos in vitro.

The effect of exposure of embryos to interferon was tested because this product of viral infection has been reported to interfere with cell division (14). Although no effect was demonstrated with a concentration of interferon of 24 units $/ \mathrm{ml}$ in culture fluids, tests with higher concentrations are required before it can be concluded that cleavage in early embryos is unaffected by interferon.

\section{REFERENCES AND NOTES}

1. Baranska, W., Sawicki, W., and Koprowski. H.: Infection of mammalian unfertilized and fertilized ova with oncogenic viruses. Nature, 230:591 (1971).

2. Berkovich, S.: An attempt to infect with virus the early rabbit embryo maintained in vitro. Abstracts of the 33rd Annual Meeting of the Society for Pediatric Research. p. 81 (Society for Pediatric Research, Atlantic City, 1963).

3. Biczysko, W., Solter, D., Pienkowski, M., and Koprowski, H.: Interactions of early mouse embryos with oncogenic viruses - simian virus 40 and polyoma. I. Ultrastructural studies. J. Nat. Can. Inst., 51: 1945 (1973).

4. Chase, D. G., Winters, W., and Piko, L.: Replication of human adenovirus in cultured mouse embryos. J. Cell Biol., 55: 39a (1972).

5. Dudgeon, J. A.: Infective causes of human malformations. Brit. Med. Bull., 32 77 (1976).

6. Gwatkin, R. B. L.: Effect of viruses on early mammalian development. I. Action of mengo encephalitis virus on mouse ova cultivated in vitro. Proc. Nat. Acad. Sci., 50: 576 (1963)

7. Gwatkin, R. B. L. Effect of viruses on early mammalian development. II Synthesis of mengo encephalitis virus by mouse ova maintained in vitro. J. Cell Biol., 23: 40A (1964).

8. Gwatkin, R. B. L.: Effect of viruses on early mammalian development. III Further studies concerning the interaction of mengo encephalitis virus with mouse ova. Fertil. Steril., 17: 411 (1966).

9. Gwatkin, R. B. L. and Auerbach, S.: Synthesis of a ribonucleic acid virus by the mammalian ovum. Nature, 209: 993 (1966).

10. Hanks, J. H. and Wallace, R. E.: Relation of oxygen and temperature in the preservation of tissues by refrigeration. Proc. Soc. Exp. Biol. Med., 7I: 196 (1949).

11. Hardy, J. B.: Fetal consequences of maternal viral infection in pregnancy. Arch Otolaryngol., 98: 218 (1973).

12. Hassan, S. A. and Cochran, K. W.: Effects of reovirus type 1 on the developing mouse embryo. Amer. J. Pathol., 55: 147 (1969).

13. Johnson, K. P.: Mouse cytomegalovirus: placental infection. J. Infect. Dis., /20: 445 (1969).

14. Lindahl-Magnusson, P., Leary, P., and Gresser, I.: Interferon and cell division. VI. Inhibitory effect of interferon on the multiplication of mouse embryo and mouse kidney cells in primary cultures. Proc. Soc. Exptl. Biol. Med., I38: 1044 (1971).

15. Medearis, D. N.: Mouse cytomegalovirus infection. III. Attempts to produce intrauterine infections. Amer. J. Hyg., 80: 113 (1964).

16. Mohanty, S. B. and Bachmann, P. A.: Susceptibility of fertilized mouse eggs to minute virus of mice. Infect. Immunol., 9: 762 (1974).

17. Neighbour, P. A.: The effect of maternal cytomegalovirus infection and preimplantation development in the mouse. J. Reprod. Fertil., 48: 83 (1976).

18. Rafferty, K. A.: Methods in Experimental Embryology of the Mouse. p. 24-32 (Johns Hopkins Press. Baltimore and London, 1970).

19. Sawicki, W., Baranska, W., and Koprowski, H.: Susceptibility of uniertilized and fertilized mouse eggs to simian virus 40 and Moloney sarcoma virus. J. Nat. Cancer Inst., 47: 1045 (1971).

20. Siem, R. A., Ly, H., Imagawa, D. T., and Adams, J. M.: Influenza virus infections in pregnant mice. J. Neuropath. Exptl. Neurol.: 19: $125(1960)$.

21. Soike. K.: Coxsackie B-3 virus infection in the picgnant mouse. J. Infect. Dis., 117: 203 (1967).

22. Tuffrey, M., Zisman, B., and Barnes, R. D.: Sendai (parainfluenza 1) infection of mouse eggs. Brit. J. Exptl. Pathol., 53: 638 (1972).

23. Whitten, W. K.: Nutrient requirements for the culture of preimplantation embryos in vitro. Adv. Bioscie., 6: 129 (1970).

24. This research was supported by research grant HD 04110 from the National Institute of Child Health and Human Development, Bethesda, MD. USA

25. Requests for reprints should be addressed to: A. D. Heggie, M. D.. Department of Pediatrics. Rainbow Babies and Childrens Hospital, 2101 Adelbert Road. Cleveland, $\mathrm{OH} 44106$, USA.

26. Received for publication April 26, 1978

27. Accepted for publication August 15,1978 . 